\title{
Improvement of the Efficiency of Adolescents' Interpersonal Interaction in Conflict Resolution
}

\section{Mejora de la eficiencia de la interacción interpersonal de los adolescentes en la resolución de conflictos}

\author{
Yanina Vasilievna Shimanovskaya \\ Head of the Department of Social Work, Russian State Social University, Moscow, Russia \\ ORCID: https://orcid.org/0000-0003-0282-1323 \\ Alexander Sergeevich Sarychev \\ Professor of the Department of Hygiene and Medical Ecology, Northern State Medical \\ University, Arkhangelsk, Russia \\ ORCID: https://orcid.org/0000-0003-3064-9145
}

Received 09-08-20 Revised 10-10-20

*Correspondence

Email: sergeeva198262@mail.ru
Cite as:

Vasilievna, Y., \& Sergeevich, A. (2021). Improvement of the Efficiency of Adolescents' Interpersonal Interaction in Conflict Resolution. Propósitos y Representaciones, 9(SPE2), e989. Doi: http://dx.doi.org/10.20511/pyr2021.v9nSPE2.989

(c) Universidad San Ignacio de Loyola, Vicerrectorado de Investigación, 2021. 


\section{Summary}

The relevance of the examined problem results from the fact that the adolescents' behaviour and their inability to overcome conflict situations are of an acute social nature. In this regard, the article is aimed at identifying the causes of early motherhood and finding ways to solve the problem in the context of social and pedagogical work. The leading research methods of this problem are psychological techniques that allow one to identify the causes of interpersonal conflicts among adolescents and to develop credible practical recommendations aimed at improving the efficiency of adolescents' interpersonal interaction. Based on the obtained data, the authors have developed specific diagnostic, correctional and training programs for behaviour correction in particular conflict situations.

Keywords: interpersonal conflict, adolescents, conflict resolution methods.

\section{Resumen}

La relevancia del problema examinado se debe al hecho de que el comportamiento de los adolescentes y su incapacidad para superar situaciones de conflicto son de carácter social agudo. En este sentido, el artículo tiene como objetivo identificar las causas de la maternidad temprana y encontrar formas de solucionar el problema en el contexto del trabajo social y pedagógico. Los principales métodos de investigación de este problema son las técnicas psicológicas que permiten identificar las causas de los conflictos interpersonales entre los adolescentes y desarrollar recomendaciones prácticas creíbles destinadas a mejorar la eficiencia de la interacción interpersonal de los adolescentes. A partir de los datos obtenidos, los autores han desarrollado programas específicos de diagnóstico, corrección y formación para la corrección de conductas en situaciones de conflicto particulares.

Palabras clave: conflicto interpersonal, adolescentes, métodos de resolución de conflictos.

\section{Introducción}

While reflecting on the problem of conflicts, it should be noted that in society, in the interpersonal relations, there are always prerequisites for conflicts, for example, the objectively limited resources (natural, social, psychological) and the associated opposition of human interests, as well as their opinions, views and ideas concerning the same reality: natural, social, etc. (Klar, Bar-Tat, Kruglanski, 1988; Voss, Wiley, 1995). It is also important to take into account that people with different education, life experience, individual character traits and temperament, etc. participate in joint activity systems. These differences inevitably affect opinions and judging on issues that are significant for people; sometimes they give rise to confrontation, which is often accompanied by emotional excitement and turns into a conflict (Borodkin, Koryak, 1983; Sheldon, 1982; White, 1984).

Each conflict situation has an objective content (which is determined by the events in reality) and a subjective meaning (which depends on the interpretation of these events by each party). The subject begins to act in the conflict in accordance with it. The subjective reflection of a conflict situation does not necessarily correspond to the actual state of affairs (Grishina, 2000; Fisher, 1990; Pruitt et al., 1993).

It is advisable to pay attention to the consideration of the personality factor, namely, the adolescents' characteristics, expressed in the tendency to react to a conflict situation in one way or another. In other words, it is the style features of behaviour in a conflict situation.

\section{Literature review}

The choice of behaviour strategy in a conflict is determined by many factors. As it was noted by N.V. Grishina, the description of the determinants of people's behaviour in a conflict situation requires referring to three groups of factors: "objective" factors of the situation, 
personal and social determinants (Grishina, 2000). The factors of the situation that determine the interaction of the participants of the conflict, their choice of certain strategies and tactics of behaviour and, consequently, the development of the conflict process are the general context of the conflict situation and the presence of factors that either complicate or mitigate the confrontation between the parties (Geen, 1990; Porter, Moore, 1981).

The conflict goes through several stages. Usually, it is preceded by a conflict situation, following which the conflict develops. "A conflict situation is the accumulated contradictions associated with the activities of the subjects of social interaction that create the basis for a real confrontation between them" (Emelyanov, 2001; Brewer, 1986; Miller, Davidson-Podgorny, 1987).

A conflict is a real confrontation of the participants in a situation, the beginning of which is the considering of the situation as a conflict and the transition to conflict interaction. The behaviour strategies chosen by the participants in the conflict are crucial for its subsequent development, and often for the final result and the outcome of the conflict (Dmitriev, Latynov, 2000; Milgram, 1992; Tannen, 1995; Medvedeva, Shimanovskaya, 2018).

Psychological orientations and attitudes of the participants of the conflict are crucial for the choice of behaviour in the social situation of interaction. Usually, the concept of a psychological attitude is a more or less stable complex of cognitive and motivational orientations towards a given situation. Socio-perceptual aspects of the conflict include the idea of the adequacy of the conflict situation reflection and the image of the "opposite". It is the perception of the situation as a conflict that creates the conflict: it launches the need for the subject to respond in the form of choosing an appropriate strategy for conflict interaction and its subsequent development (Libin, 1999; Deutsch, 1985; Stephan, 1985).

\section{Methods}

To identify the influence of adolescents' characteristics on the choice of style features in conflict resolution, a study "Adolescents' behaviour strategies in conflict situations" was conducted in the Moscow region in 2019. The study was aimed at developing recommendations for improving social and psychological assistance to pregnant adolescents and adolescent mothers and for early pregnancy prevention.

The objects of the study were 150 adolescents at the age of 12 and 13 in the Moscow region. A mandatory condition for inclusion in the survey was the voluntary written consent of the adolescents' legal representatives.

For the study we used: the Shmishek test of personality accentuation; Eysenck's method for assessing mental states (respondents were offered a description of four mental states: anxiety, frustration, aggressiveness, rigidity); "Self-assessment" method (designed for quantitative diagnostics of the level of self-esteem and self-attitude); the Thomas-Kilmann Conflict Mode Instrument (a technique that determined the respondents' most frequent style of behaviour in a conflict).

\section{Result and Discussion}

Initial analysis of the results of the Shmishek test of personality accentuation makes it possible to reveal that, in general, modern adolescents demonstrate an average level of demonstrativeness (12.4 points). In other words, modern adolescents, especially girls, are characterized by demonstrativeness. High level of demonstrativeness of girls is the result of active assimilation of the sexual role, which is natural at the given age (Medvedeva, Shimanovskaya, 2018). Boys show a lower level of demonstrativeness. 
Boys and girls do not significantly differ from each other on the "stuck" scale (8.8 and 9.6 points respectively), i.e. girls are a little more likely to get "stuck". Yet, the rest of the girls and boys show a minimal tendency towards getting "stuck"; they rarely tend to affections (truthfulness, resentment, jealousy, suspicion) and they are rarely arrogant.

The scores on the "pedantic" scale are the lowest (4.6 points); none of the respondents neither demonstrate this type of accentuation itself nor even a tendency to it. In other words, the surveyed boys and girls do not differ from each other in terms of accuracy, indecision and caution, which are the characteristics of pedantic accentuation.

On the whole, $24 \%$ of the respondents demonstrate excitable accentuation. To be more precise, $8 \%$ of the girls and $16 \%$ of the boys are characterized by rather high excitability, insufficient controllability, weak control over affections, predominance of hedonistic emotions and impulsivity. Boys of this type are especially characterized by anger and rudeness; they are inclined to confrontations, conflicts, abuse and impertinent answers.

The "hypertensive" scale has the maximum scores: 15.9 points. In general, $48 \%$ of the respondents have this accentuation. Almost half of the boys and girls (44\% of the girls and $52 \%$ of the boys) are very active, mobile and sometimes even disinhibited. They are sociable, sometimes too independent, energetic, active and initiative. Their interests are unstable and superficial. These are people with high self-esteem; therefore, they sometimes tend to immoral acts and high irritability in case of failure (Libin, 1999). The rest of the boys and girls are less irritable and more tolerant in communication with others; they are more serious about their duties.

Dysthymic accentuation is a concentration on the gloomy, sad aspects of life. Practically, it is not a characteristic of the surveyed respondents, neither boys nor girls (average group result: 9.7 points). Anxiety and concern about possible failures are almost not demonstrated by modern boys and girls; they are quite confident in their abilities.

Affective accentuation is the scale that has the maximum scores (15.2 points is the average for the group). $36 \%$ of the girls and almost $60 \%$ of the boys have an excessively joyful, carefree perception of life. Such people often argue, but they do not come to open conflicts; they are attached to friends and relatives and are altruistic. The rest of the respondents demonstrate these qualities to a lesser extent.

Cyclothymicity is another personal trait manifested by the overwhelming majority of the surveyed respondents: the average group score is 15.4 points. $57 \%$ of the girls and $43 \%$ of the boys are characterized by a change of hypertensive and dysthymic states, frequent mood changes, as well as dependence on external events. Moreover, the girls more often show a tendency to manifest the features of this accentuation and the boys are more often accentuated.

Analysis of the results of Eysenck's method for assessing mental states makes it possible to note that the surveyed adolescents demonstrate low and medium levels of anxiety, which corresponds to the age norm: self-esteem is often high, and anxiety is reduced due to the psychological defences at this age. Only $10 \%$ of the girls demonstrate a high level of anxiety. This may be the result of the decreased level of 
self-acceptance ("Self-assessment" method). None of the boys show a high level of anxiety.

The respondents show a low level of frustration (6 points), i.e. their needs are often met and these people are quite confident in themselves. The average level of aggressiveness is between medium and high levels (14 points). Moreover, girls almost do not lag behind boys in this parameter (13.5 and 13.8 points respectively). Only $46 \%$ of the girls and $42 \%$ of the boys show medium and low levels of aggressiveness. In other words, generally, they are not aggressive, but in a situation of threat, they will be able to stand up for themselves. The rest of the respondents are excessively aggressive, they can resort to aggression not only to protect themselves, but also on their initiative, to achieve their goals.

The respondents show a medium level of rigidity, easy switching and situational flexibility, which corresponds to the age norm (rigidity increases with age). The girls show the highest level of rigidity; in comparison with the boys, they are more likely to act within the established norms and rules. They are more stable and less inclined to social experimentation.

In general, the self-esteem of the surveyed respondents is at the medium level (0.61 points). The self-esteem of the boys is slightly higher than that of the girls $(0.63$ and 0.69 points respectively). $28 \%$ of the girls and $30 \%$ of the boys demonstrate an inadequately high level of self-esteem, $56 \%$ of the girls and $54 \%$ of the boys demonstrate adequate self-esteem and $18 \%$ of the girls and $16 \%$ of the boys underestimate themselves. High self-esteem is a sign of psychological protection from increased internal stress, i.e. the inner tension of the boys is higher than that of the girls. We can assume that the psychological distress of the boys is due to conflicting genderrole prescriptions and their mastering is one of the first tasks of adolescence.

Analysis of the results of the Thomas-Kilmann Conflict Mode Instrument makes it possible to note that the collaborating style of behaviour in conflict is the second most popular among the respondents. Both boys and girls have already learned to take into account the opinion of the other party. Egocentrism is more often replaced by partnership, and the development of reflection and the ability to analyse the situation makes boys and girls less combative. It is interesting, that boys are slightly more collaborative than girls (6.9 and 6.6 points respectively). Perhaps, girls are a little less collaborative than boys due to the high level of demonstrativeness, the desire to be in the focus of attention and, accordingly, due to the fear of being wrong in front of everyone. Competing style is the most preferred method of conflict resolution (7.6 points). The predominance of this method can be explained by the puberty. Boys are traditionally slightly more competitive than girls (7.7 and 7.5 respectively). Compromising style is in the third place in terms of frequency of use (6.4 points). Girls tend to make concessions more often than boys (6.4 and 6.3 points respectively).

Significant linear correlation coefficients obtained by processing the results of all the respondents show the relationship between personality traits and styles of behaviour in conflict of both boys and girls. 


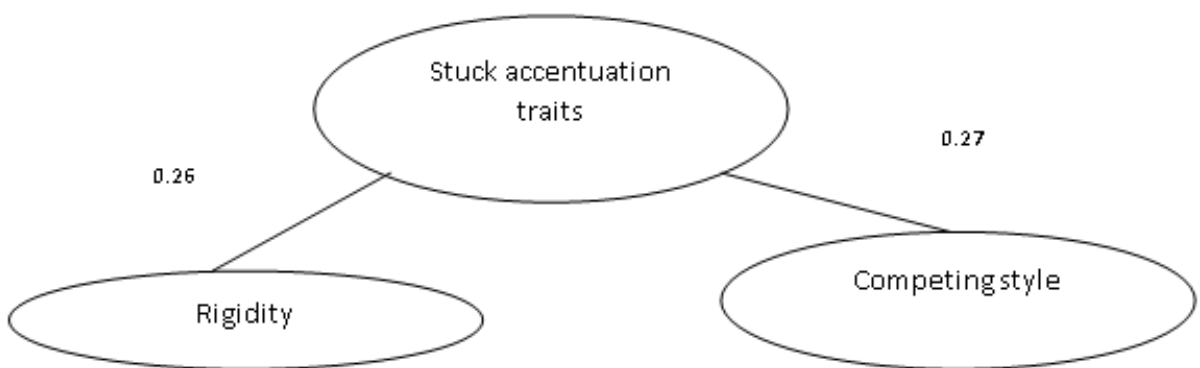

(Figure 1): Correlation of the connection between the accentuation, style of behaviour in conflict and other personality traits

Thus, if in the character of a modern adolescent we observe the predominance of traits of stuck accentuation (Fig. 1), then with a high degree of probability we can predict that this adolescent will use the competing style of behaviour in a conflict (0.27). Besides, the adolescents will also show a high level of rigidity and will persist in their own (0.26), which is probably an obstacle to the use of more peaceful styles of behaviour in conflict, for example, collaborating or compromising style.

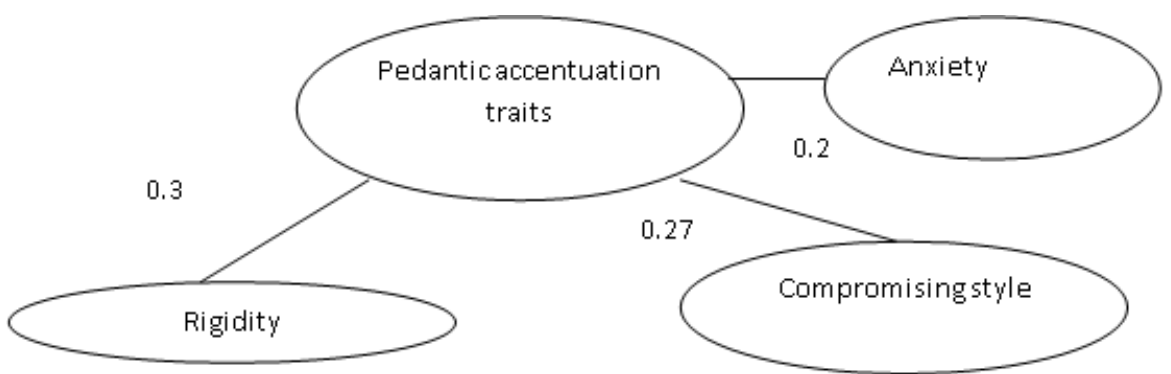

(Figure 2): Correlation of the connection between the accentuation, style of behaviour in conflict and other personality traits

The more there are features of pedantic accentuation in the character of a modern adolescent (Fig. 2), the more this adolescent tends to compromise (0.28) and the more this adolescent is ready to make concessions in the conflict. Pedantic adolescents are prompted to seek compromises by the predominance of anxiety $(0.2)$ and rigidity in their mood, i.e. they tend to the order and the observance of equality rules (0.3). If excitable accentuation is predominant in the character of a modern adolescent (Fig. 3), then in the overwhelming number of conflicts, this adolescent will not use the collaborating style (-0.2) and will not avoid conflicts and quarrels (-0.27). On the contrary, this adolescent will be either the active instigator or successor or, in other words, will compete (0.38). This adolescent will use these particular styles in conflict because of the increased aggressiveness, irascibility (0.23) and low rigidity, i.e. mobility of moods and beliefs, impulsivity (-0.2).

The predominance of hypertensive accentuation traits (Fig. 3) gives only negative connections. We can state that these adolescents will not use the collaborating style (-0.28) and accommodating style (-0.25) in the conflict. They are likely to differ in their choice of a particular style of behaviour in conflict, so there is no agreement in the results and no positive connections. 


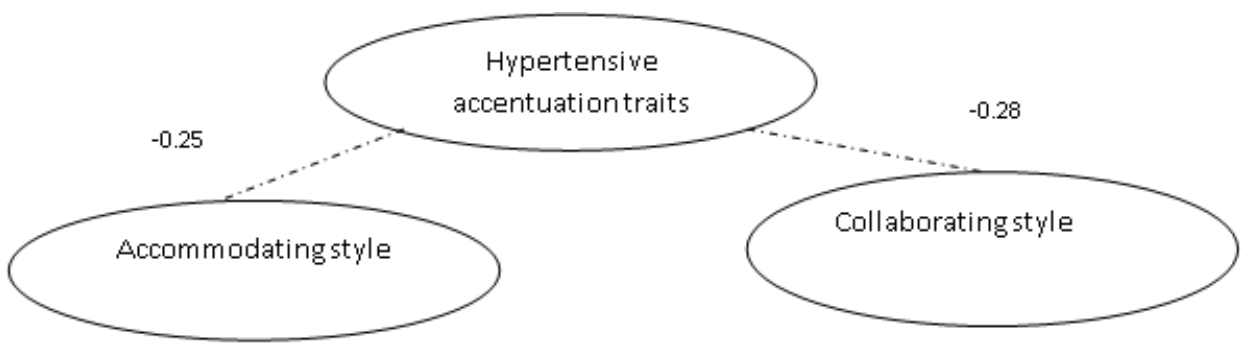

Source: the authors

(Figure 3): Correlation of the connection between the accentuation, style of behaviour in conflict and other personality traits

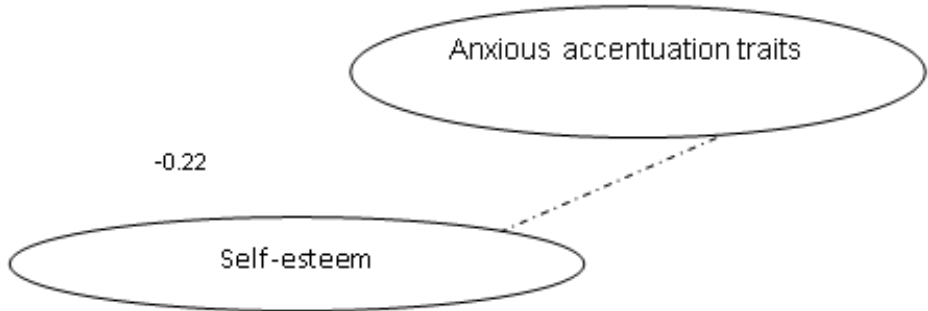

Source: the authors

(Figure 4): Correlation of the connection between the accentuation, style of behaviour in conflict and other personality traits

The predominance of anxious accentuation traits (Fig. 4) is associated only with a decrease of self-esteem $(-0.22)$; the most probable style of behaviour in the conflict is not found. It can also be said that the higher is the self-esteem of modern adolescents (which we observe in the survey), the fewer are the features of anxious accentuation.

The predominance of affective accentuation traits (Fig. 5), cheerful mood and high spirits leads to the fact that in most conflicts adolescents will not use the avoiding style (-0.26), but will collaborate $(0.24)$ and look for the ways that are acceptable to both parties. Demonstrative, dysthymic, emotive and cyclothymic accentuations show no significant connection. This means that boys and girls with these personality traits do not have any probable choice of the style of behaviour in a conflict; they choose different styles, so it is difficult to predict their behaviour.

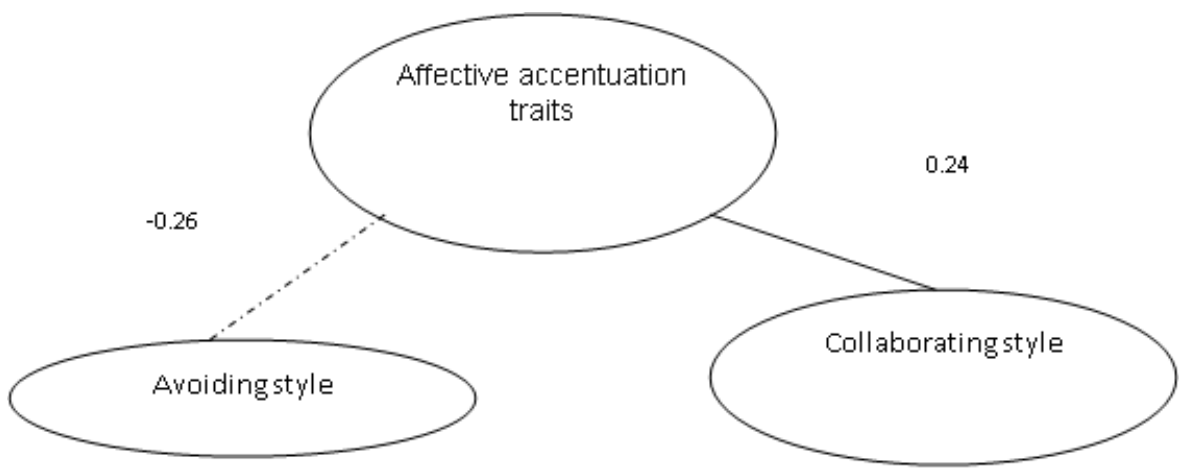

Source: the authors

(Figure 5): Correlation of the connection between the accentuation, style of behaviour in conflict and other personality traits

The choice of a style of behaviour in a conflict is also not influenced by the level of frustration (there are no significant connections). Self-esteem influence the choice of 
a style of behaviour in a conflict minimally (one significant connection). In other words, neither the level of realization of desires and interests nor the level of self-esteem determines the unambiguous choice of a particular style of behaviour in a conflict.

\section{Conclusion} indicators:

Thus, the results of the study made it possible to identify differences in the follow-ing

1. In terms of the level of anxiety $(p=0.044)$, girls are significantly more anxious than boys. than boys.

2. In terms of the level of frustration $(p=0.022)$, girls are significantly more frustrated

3. In terms of the level of rigidity $(\mathrm{p}=0.042)$, girls are significantly more rigid than boys.

4. In terms of the level of representation of demonstrative traits in the charac-ter $(p=$ 0.070), girls are significantly more demonstrative than boys.

5. In terms of the level of representation of stuck traits in the character $(p=0.020)$, girls are significantly more likely to get stuck than boys.

6. In terms of the level of representation of traits of excitable traits in the character $(\mathrm{p}=$ 0.025), girls are significantly less excitable than boys.

7. In terms of the level of representation of anxiety traits in the character $(p=0.025)$, girls are significantly more anxious than boys.

In terms of the degree and frequency of the use of a particular style of be-haviour in a conflict, no significant differences between boys and girls are found during the study. Adolescents are equally likely to use different methods of resolv-ing interpersonal conflicts.

\section{Referencias}

Borodkin, F.M., Koryak, N.M. (1983). Vnimanie: konflikt! [Attention: the conflict!]. Moscow: Nauka.

Grishina, N.V. (2000). Psikhologiya konflikta [The psychology of a con-flict]. Saint Petersburg: Piter.

Dmitriev, A.V., Latynov, V.V. (2000). Konflikt [Conflict]. Prikladnaya psikhologiya, 1, 16-27.

Emelyanov, S.M. (2001). Praktikum po konfliktologii [Conflict management workshop]. Saint Petersburg: Piter.

Libin, A.V. (1999). Differentsialnaya psikhologiya: na peresechenii evro-peiskikh, rossiiskikh i amerikanskikh traditsii [Differential psychology: at the intersection of European, Russian and American traditions]. Moscow: Smysl.

Brewer, M.B. (1986). The role of ethnocentrism in intergroup conflict. In S. Worchel and W.G. Austtin (Eds.) Psychology of intergroup relations (p. 88-102). Chicago: Nelson-Hall.

Deutsch, M. (1985). Distributive justice: A social psychological perspective. New Haven: Yale University Press.

Fisher, R.J. (1990). The social psychology of intergroup and international conflict resolution. New York: Springer-Verlag.

Geen, R.G. (1990). Human aggression. Pacific Grove: Brooks. 
Klar, Y., Bar-Tat, D., Kruglanski, A. (1988). Conflict as a Cognitive Schema: Toward a Social Cognitive Analysis of Conflict and Conflict Termination. The Social Psychology of Intergroup Conflict. Theory, Research and Applications. Berlin.

Medvedeva, G.P., Shimanovskaya, Ya.V. (2018). Well-being as meaning of social-andhumanitarian activities. RPTSS 2018 - international conference on research paradigms transformation in social sciences. European Proceedings of Social and Behavioural Sciences, 50, 778-784.

Miller, N., Davidson-Podgorny, G. (1987). Theoretical models of intergroup relations and the use of cooperative teams as an intervention for desegregated settings. In C. Hcndrick (Ed.), Group processes and intergroup relations. New-bury Park: Sage.

Milgram, S. (1992). The individual in a social world: Essays and experiments (2nd ed.). New York: McGraw-Hill.

Porter, R.H., Moore, J.D. (1981). Human kin recognition by olfactory cues. Physiology \& Behavior, 27, 112-128.

Pruitt, D.G., Micolic, J.M, Eberle, R., Parker, J.C., Peirce, R.S. (1993). The escalation of conflict: Group vs. individual response to persistent annoyance. Sixth Annual Conference of the International Association for Conflict Management, Houthalen, Belgium.

Sheldon, B. (1982). Behavior Modification: Theory, Practice and Philosophy. New York: Tavistock.

Stephan, W.G. (1985). Intergroup relations, In: G. Lindzey, A. Aronson (Eds.), Handbook of social psychology (vol. 2, p. 599-658). New York: Random.

Tannen, D. (1995). Yo u Just don't Understand. New York.

Voss, J., Wiley, J. (1995). Acquiring Intellectual Skills. Annual Review of Psychology, 46, $155-181$

White, R.K. (1984). Fearful warriors: A psychological profile of U.S.-Soviet relations. New York: Free Press. 